\title{
Interaction Gaps in PhD Education and ICT as a Way Forward: Results from a Study in Sweden
}
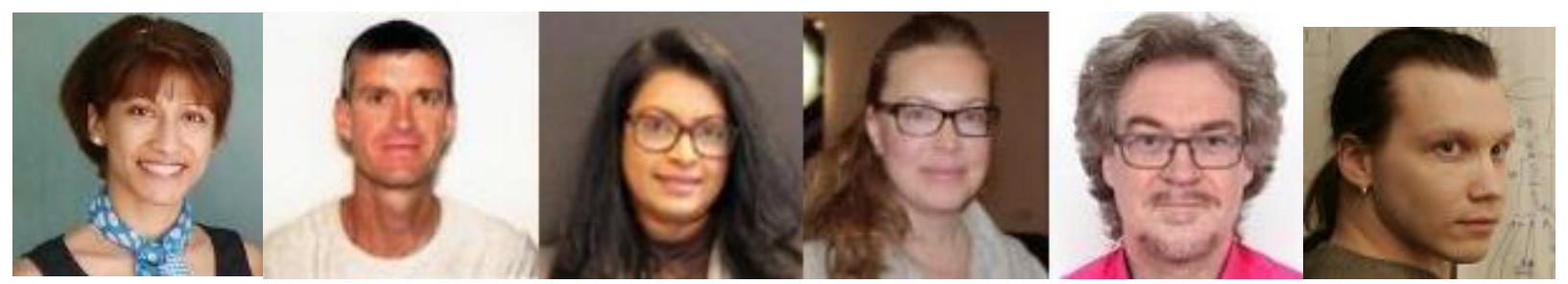

Naghmeh Aghaee ${ }^{1}$, William Byron Jobe², Thashmee Karunaratne ${ }^{3}$, Åsa Smedberg $^{4}$, Henrik Hansson ${ }^{5}$, and Matti Tedre ${ }^{6}$ Stockholm University'1,3,5,6, University West ${ }^{2}$,

\begin{abstract}
Many research studies have highlighted the low completion rate and slow progress in $\mathrm{PhD}$ education. Universities strive to improve throughput and quality in their PhD education programs. In this study, the perceived problems of $\mathrm{PhD}$ education are investigated from $\mathrm{PhD}$ students' points of view, and how an Information and Communication Technology Support System (ICTSS) may alleviate these problems. Data were collected through an online open questionnaire sent to the PhD students at the Department of (the institution's name has been removed during the double-blind review) with a $59 \%$ response rate. The results revealed a number of problems in the $\mathrm{PhD}$ education and highlighted how online technology can support $\mathrm{PhD}$ education and facilitate interaction and communication, affect the $\mathrm{PhD}$ students' satisfaction, and have positive impacts on PhD students' stress. A system was prototyped, in order to facilitate different types of online interaction through accessing a set of online and structured resources and specific communication channels. Although the number of informants was not large, the result of the study provided some rudimentary ideas that refer to interaction problems and how an online ICTSS may facilitate $\mathrm{PhD}$ education by providing distance and collaborative learning, and PhD students' self-managed communication.
\end{abstract}

Keywords: PhD education, information and communication technology (ICT), support system, interaction, peer communication.

\section{Introduction}

The use of educational technology in higher education enables new affordances for information gathering, communication, and learning. In many ways, online ICT (information and communication technology) 
systems facilitate the acquisition of information (Tinio, 2003; Abbott, 2003), provide support for transferring knowledge and collaborative learning (McCormick, 2004), and advance the different types of interaction (Moore, 1989; Moore \& Kearsley, 1996). ICT support systems (ICTSSs) increase learners' motivation by facilitating the interactions synchronously or asynchronously with real people and even provide opportunities to participate in real world events (Tinio, 2003).

Communication channels and information resources play important roles in education and collaborative learning by facilitating interactions. According to Moore (1989) there are three types of interactions for distance learning: (a) between the learner and the instructional and informative contents (learner-content interaction), (b) between the learners and the instructors or supervisors (learner-supervisor interaction), and (c) among learners (peer interaction). Since learners in the PhD education face similar challenges, opportunities, and threats as learners in distance education, an ICTSS facilitates different types of interaction in the PhD education. In this study, the learner refers to the PhD student and the instructor refers to the PhD student's supervisor or co-supervisors.

As Kyvik and Olsen (2013) mention, many PhD students (doctoral students) never complete their degrees and relatively few students succeed in obtaining their doctorates within the stipulated time period. There are different factors and core competencies that may affect the $\mathrm{PhD}$ education (doctoral education) process and success of the PhD students (Durette, Fournier, \& Lafon, 2014). Insufficient learnerinstructor interaction is an important issue, although the shortage of learner-instructor interaction is not merely the reason for the problems in the learning process in higher education (Christie \& Jurado, 2013; Jones, 2013; Aghaee, Hansson, Tedre, \& Drougge, 2014). As discussed by Lindén, Ohlin, and Brodin (2013), the learners perceive a lack of role model learning in their $\mathrm{PhD}$ education, while their perceived aims for supervision are partly achieved.

Another part of the problem in $\mathrm{PhD}$ education is insufficient peer communication and lack of contact with other PhD students (discussed by Christie \& Jurado, 2013; Guilford, 2001; Kyvik \& Olsen, 2013; Reference deleted during double-blind review). As mentioned by numerous studies (see for instance Ali \& Kohun, 2007; Delamont, Atkinison, \& Parry, 2004; Hockey, 1991; Wright \& Lodwick, 1989; Welsh, 1980; Reference deleted during double-blind review), $\mathrm{PhD}$ students' isolation and lack of communication is an important problem and there is a need for $\mathrm{PhD}$ students to be situated within social groups or be supported to have better communication channels to interact with their peers. As in many other universities worldwide, in Sweden, (the institution's name has been removed during the double-blind review) most online communications among learner-supervisor or learner-co-supervisors and peers are limited to email. There are no unified additional tools or ICTSS for the distance communication and learning in $\mathrm{PhD}$ education. This lack of resource has contributed to PhD students' isolation and lack of proper communication with their supervisors and peers.

In addition, a shortage of structured e-resources and concrete guidelines is also another part of the problem in higher education as well as a problem in education at the bachelor's and master's levels (Jones, 2013; Aghaee, Karunaratne, Smedberg, \& Jobe, 2015; Aghaee et al., 2014). There is no online support for $\mathrm{PhD}$ education, from which $\mathrm{PhD}$ students can remotely access and learn from the online and structured resources. However, PhD education is about distance learning and independent research. There is a shortage of structured information resources and communication channels to facilitate interactions 
(Christie \& Jurado, 2013; Jones, 2013; Aghaee et al., 2014) both on campus and especially for distance education and communication. In many institutions, there are not enough available information resources aligned with the goals of PhD education to guide the PhD students (Christie \& Jurado, 2013; Guilford, 2001; Kyvik \& Olsen, 2013; Aghaee, et al., 2015). Peer communication is also helpful for supporting information acquisition and transferring information (Reference deleted during double-blind review).

Insufficient communication channels or structured information resources cause difficulties for the $\mathrm{PhD}$ students to know what research involves (Haksever \& Manisali, 2000). Problems such as not receiving important information on time, not being aware of rules and regulations of the $\mathrm{PhD}$ process, or not getting information about the time constraints, create confusion for PhD students, and hence consequently cause disturbances in concentration for their research. This negatively influences PhD students' ability to finish their PhD studies on time or not at all (Jones, 2013). This case is even worse for the PhD students who are rarely on campus, since the distance communication is poor and non-supportive to educate learners at higher levels.

Lack of the availability of online ICTSS and distance support has some negative impacts on the quality of the outcomes of the PhD studies and may increase the stress ${ }^{1}$ level for the PhD students. In this study, stress refers to a lack of control of the situation, worriment, or emotional tension due to a lack of keeping track of the study process and getting nervous due to insufficient information and communication and lack of remote access to the required information and missing the important issues. There is a stress reaction when an individual experiences a difficult situation as a threat; something with which he or she cannot cope (Lazarus \& Folkman, 1984). The relationship between perceived demands and perceived control of work is critical for the reactions. For example, high demands in combination with a low level of control are associated with negative stress reactions (Karasek \& Theorell, 1990).

This study systematically investigated the PhD students' perspectives regarding the most challenging issues that negatively impacted their PhD studies. Moreover, this study evaluated the PhD students' perceptions of usefulness of an ICTSS in PhD education. In order to shed some light on these issues, the following research questions were constructed:

1. What are the most important problems in $\mathrm{PhD}$ education from $\mathrm{PhD}$ students' perspectives?

2. How do PhD students think that an ICTSS will facilitate reducing interaction problems and stress in a PhD education?

In this study, we investigate the PhD students' perspectives on insufficient supervision or lack of communication with supervisors. Moreover, in this study, other issues such as a lack of peer communication and a lack of structured information, which may have negative effects on the process and quality of the PhD studies, are also investigated. Based on the result of this study and the PhD students' requirements, an ICTSS for PhD studies was developed and tested at the department. The ICTSS is aimed at reducing problems and challenges in $\mathrm{PhD}$ education to provide more control on the study process, to

\footnotetext{
${ }^{1}$ Stress is a state of mental or emotional strain, tension, or suspense that causes worry or emotional tension, and results from adverse or very demanding circumstances.
} 
facilitate accessing related e-resources, to support flexible and distance learning, and to plan better and provide quicker updates to reduce the stress and enhance the control of the situation. The methodology used in this study was an online open survey, sent out to all the PhD students at the department (the institution's name has been removed during the double-blind review).

\section{Related Studies}

As discussed by Lindén et al. (2013), a PhD education is intended to prepare $\mathrm{PhD}$ students for professional work within and outside academia and hence, it is important that students' personal learning is supported to a greater extent. A number of studies have investigated PhD students' and supervisors' perceptions about the quality, effectiveness, and problems of supervision in the PhD study process (Christie \& Jurado, 2013; Lönn Svensson, 2007; Lindén, 1998; Lindén et al., 2013; Sinclair, 2004; Handal \& Lauvås, 2008; Delamont et al., 2004; Wisker, 2012; Shannon, 1995). Lindén et al. (2013) argued about the lack of congruence in participants' perceptions that points to underlying problems related to such interaction problems. However, there are not many relevant studies available about using ICT as a complement to personal supervisions to filling the interaction gaps in $\mathrm{PhD}$ studies. How to use technology in higher education as a support to reduce the problems is still a challenge (Richards, 2005; Richards, 2006). The study by Christie and Jurado (2013) shows that senior supervisors or professors often do not provide sufficient support since they are normally too busy with seeking funding, building networks, and doing other tasks. Christie and Jurado (2013) discuss this issue as a significant issue for the PhD study process.

The first question that may come to mind with respect to $\mathrm{PhD}$ studies is what is a $\mathrm{PhD}$ degree? Different researchers (such as Kandiko \& Kinchin, 2012; Fiske, 2011; Gannon, 2006; Park, 2005; Langrish, 2000) have discussed this question. Based on the discussions in different studies (such as Kandiko \& Kinchin, 2012; Fiske, 2011; Gannon, 2006; Park, 2005; Langrish, 2000), the academic level known as a PhD (abbreviation for doctor of philosophy) may vary considerably according to the country, institution, or academic discipline. In Sweden, a $\mathrm{PhD}$ is a program that nominally comprises 240 credits including a thesis of at least 120 credits that is equivalent to four years of full-time study (Högskoleverket, National Agency for Higher Education, 2012). PhD students must complete a number of courses besides writing a dissertation (thesis) and defending it at a public oral examination (Högskoleverket, National Agency for Higher Education, 2012). In Sweden, for each subject in the PhD program, there should be a general study plan that is determined by the faculty board. The general study plan shall contain a description of content and structure, and what applies for admission to a PhD program.

In addition, in most of the institutions in Sweden (the institution's name has been removed during the double-blind review), there is an individual study plan that is adjusted to the individual study situation to guide the PhD process. Based on the description that is approved by the National Agency for Higher Education, an individual study plan is a document that describes and establishes an individual curriculum and schedule for each PhD student. Moreover, the individual study plan is a description of the $\mathrm{PhD}$ student's commitments and departmental responsibilities. The study plan has to be updated annually by $\mathrm{PhD}$ students and their supervisors and needs to be approved by the department board. To specify the general regulations (the institution's name has been removed during the double-blind review), the head of the department has to approve both the general and individual study plans. 


\section{Conceptual Model}

This study investigates the issues in $\mathrm{PhD}$ studies with respect to three main themes, discussed by Moore (1989) and Moore and Kearsley (1996). Sub-themes are inspired by the model from Jones (2013) and the issues discussed and illustrated by Christie and Jurado (2013), Aghaee (2013), and Aghaee and Hansson (2013). Figure 1 illustrates the major themes comprising issues and their subcomponents.

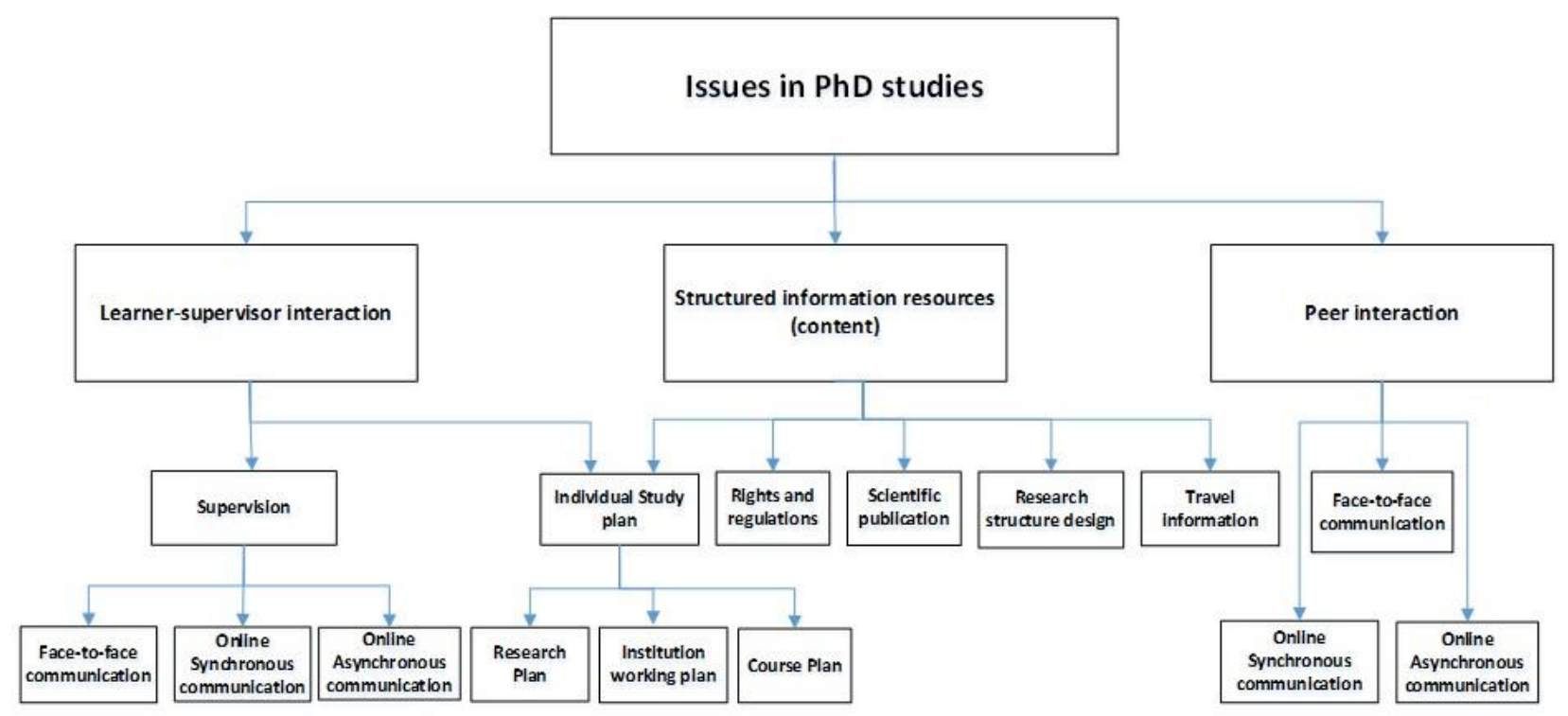

Figure 1. Educational interaction in $\mathrm{PhD}$ studies that can be enhanced with the use of an ICTSS, to facilitate flexible and distance learning and collaboration.

As discussed by different studies, there are many factors that contribute to not completing a $\mathrm{PhD}$ education at all or in some cases not finishing on time (Jones, 2013; Christie \& Jurado, 2013; McCormack, 2005; Wright \& Cochrane, 2000; Rudd \& Hatch, 1968; Welsh, 1980; Hockey, 1994). Based on the previous studies the following three categories are concluded and identified as insufficient interactions in a $\mathrm{PhD}$ education:

- Insufficient supervision: Lack of regular and coherent communication between the PhD students and their supervisor(s) for getting structured information and guidelines for the $\mathrm{PhD}$ studies. This problem is more serious for the distance PhD students, who are rarely oncampus and require more distance and online support.

- Insufficient peer communication: Lack of discussion forums, chat, or other online interactions among peers to discuss problems and situations. Learners have to deal with their study difficulties on their own and there is no systematic help or ICT support tools for the junior $\mathrm{PhD}$ students to get assistance from the senior $\mathrm{PhD}$ students and be able to regularly communicate with their peers.

- Insufficient online and structured information and lack of appropriate timelines: Insufficient information resources (content) about the goals of the PhD education and appropriate online guidelines for the PhD study process. Moreover, as discussed above, in PhD education, it is 
not clear for the $\mathrm{PhD}$ students what the requirements, milestones, or the most important issues are. The $\mathrm{PhD}$ students have no remote or distance access to the materials and important information resources, especially in the beginning of the $\mathrm{PhD}$ education, which makes them very dependent on their supervisors and requires them to be on campus to get information and guidelines.
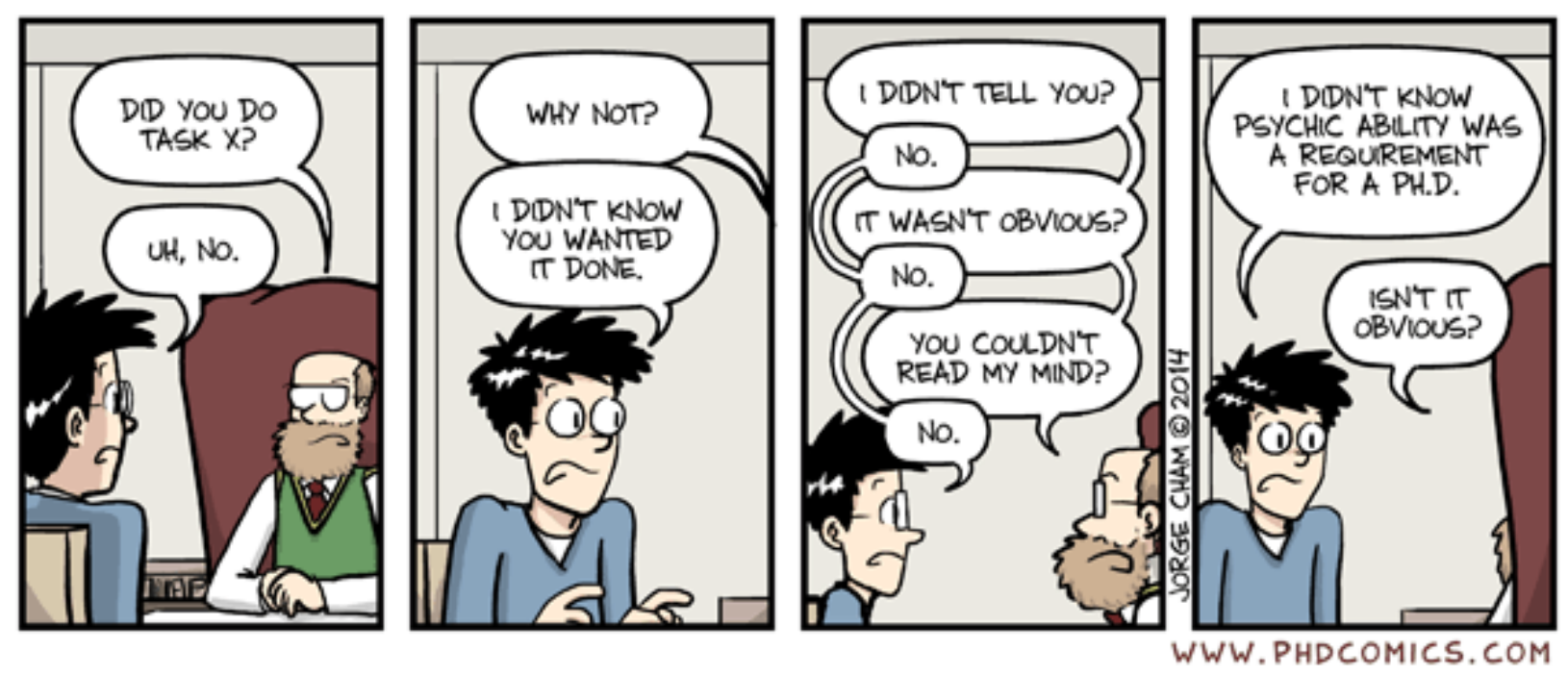

Image from PhD Comics (originally published: 2/23/2015):

http://phdcomics.com/comics/archive.php?comicid=1782

\section{Methodology}

\section{Instruments}

In order to achieve an inclusive coverage of $\mathrm{PhD}$ student population at the department-including oncampus and off-campus students as well as part-time and full-time students-this study adopted a survey strategy (Denscombe, 2010). Data were collected using online questionnaires in order to reduce turnaround time, and to gain easy and immediate access to informants (ibid.). As this study had both evaluative and exploratory aims, the questionnaire included closed- and open-ended questions (Randolph, 2007). The closed-ended questionnaire items, which constituted the quantitative part of the study, asked students about their perceptions of the importance of different aspects of their PhD studies, and about the perceived usefulness of functions of a newly designed ICTSS for PhD education. Students rated their perceptions using a four-point ordinal scale that ranged from 1 (very useful) to 4 (not useful at all). Openended questions complemented the closed-ended questions by collecting respondents' opinions and perceptions in their own words, as well as their reflections in more detail (Cohen, Manion, \& Morrison, 2007). The questions were in English, and they were designed to be self-explanatory, simple, and unambiguous, based on the guidelines of Cohen et al. (2007) and Denscombe (2010). Two postgraduate students and two senior researchers tested the questionnaire before launching it. The final questionnaire consisted of 34 questions, of which five were background questions. Of the rest, 22 were closed-ended questions, and seven were open-ended questions. 


\section{Participants}

The Web-based questionnaires were sent to all $90 \mathrm{PhD}$ students at the department in November 2013, and the last responses were received in February 2014. The questionnaire was delivered to the PhD students by email with two reminders with a time interval of one month (Lemon, 2007; Dillman, 1978). The reminders increased the overall response rate by about $10 \%$, with the final response rate being $59 \%$, which was satisfactory according to what the methodology literature reports to be within standard deviation for electronic surveys (Cook, Heath, Thompson, 2000; Dillman, 1978). However, the response rate exposed the results of this study to non-response bias through refusal (Denscombe, 2010). The participants received no benefits from participation. Informed consent was ensured at the beginning of the questionnaire as well as in the content of each email. The data collection was completely anonymous and the participants were informed about the anonymity. No private information was used or connected to any response and all the background questions were optional.

\section{Data Analysis}

The quantitative data were analyzed using SPSS (Statistical Package for the Social Sciences). Descriptive statistics of quantitative data from closed-ended questions were reported for all closed-ended questionnaire items. Associations between certain variables were analyzed by calculating Pearson's

test

for independence, and only those results that were significant at $p<0.05$ were reported. Non-responses were removed from analysis. The qualitative data were analyzed both quantitatively and qualitatively. In the quantitative analysis, results from open-ended questions were analyzed with the help of statistical text mining to show the important words that the respondents used in describing the problems they had and the solutions they proposed in order to enhance the ICTSS. A word cloud of the term frequency matrix was generated based on the responses to the open-ended questions. In the qualitative analysis, Creswell's (2012) data analysis spiral was followed. First, data were coded to pinpoint the issues and challenges in the data and separated into two categories of problems and suggestions (shown in the Appendix). The codes were interpreted and classified into similar issues. Third, those categories were situated in their context and represented with other relevant aspects in order to create a visualized account of the findings (Figure 3).

\section{Results and Analysis}

The questionnaire was sent out to $90 \mathrm{PhD}$ students and $59 \%$ of them responded. One quarter (25\%) of the 53 respondents were female. Regarding age, 83\% of the respondents were between 26 and 45 years old, and the rest were more than 45 years old. Of the respondents, $40 \%$ had been PhD students for two or less than two years, $35 \%$ between three and four years, and the rest (25\%) had been PhD students for five years or more. Three in five respondents (61.5\%) were fulltime PhD students and the rest were halftime or part time PhD students. The respondents came from 11 subject fields at the department (the institution's name has been removed during the double-blind review): business process management and enterprise modeling, cyber systems security, data and text mining, digital games, e-government and e-democracy, ICT for development, interactive design, IT management, language technology, risk and decision analysis, and technology enhanced learning.

The PhD students' opinions differed between students from different research areas. Firstly, the PhD 
students' research areas were associated with their perceived usefulness to have online access to an Idea Bank (a repository to find new research ideas and other researchers working on similar topics; $p<0.402$ ), with their perceptions towards online access to categorized information from the doctoral handbook ( $p<$ o.293), and with their perceptions towards being able to plan and maintain PhD courses online ( $p<$ 0.402). However, this may be due to the number of respondents in each area of research. For instance, there were eight respondents from the research area of risk and decision analysis, whereas there was only one respondent from the research area of immersive participation. Hence, the correlation may not correctly reflect the usefulness of the specific functions related to any specific area of research, but there may also be a connection.

Table 1 illustrates the agreement of $\mathrm{PhD}$ students with various statements about problems in their $\mathrm{PhD}$ education. The percentages in table 1 represent the agreement of the respondents with the issues in the four first closed-ended questions. Since strongly agree and agree both represent agreement, they were combined to give the percentages in Table 1. Further issues mentioned by the $\mathrm{PhD}$ students are presented in the Appendix.

Table 1

Sorted Problems Based on the Agreement of the PhD Students with the Following Issues

\begin{tabular}{lc}
\hline \multicolumn{1}{c}{ Common problem in the PhD study process } & Percent \\
\hline Insufficient online information: PhD requirements, the study process, goals, etc. & $72 \%$ \\
Insufficient online peer communication: synchronous or asynchronous interactions & $70 \%$ \\
Lack of appropriate timelines: milestones or internal deadlines & $58 \%$ \\
Insufficient supervision and lack of communication with supervisor(s) & $51 \%$ \\
\hline \hline
\end{tabular}

Table 2 covers the close-ended questions and illustrates to what extent $\mathrm{PhD}$ students may find the following resources and functionalities useful in their $\mathrm{PhD}$ studies. The percentages represent the agreement of the respondents with the usefulness of the following resources and functionalities. Since very useful and rather useful represent positive responses, they were combined to give the percentages of agreement on each question in Table 2. More details about the answers of the PhD students to the open ended questions are presented in the Appendix.

Table 2

Sorted Functionalities and Resources of the ICTSS Based on the PhD Students' Perceptions of their Usefulness

Usefulness of the ICT $4 \mathrm{PhD}$ resources and functionalities $\%$ $>=90 \%$

Online access to travel information: travel insurance, traveling steps and formalities, traveling $\quad 95.8 \%$ information about conference fees, and booking flights. 
Be able to plan and update their individual study plan online. $\quad 93.8 \%$

Online access to categorized information from the doctoral handbook. $\quad 93.3 \%$

Access to an online description and guidelines about filling in and updating the individual $\quad 92.0 \%$ study plan.

Be able to apply for and receive approval for conference expenses and other PhD related $91.7 \%$ activities.

Be able to plan and maintain PhD courses online. $\quad 91.7 \%$

Online access to the list of well-known journals in specific research area. $\quad 90.3 \%$

Online access to the publication ranking and their own publications' ranks. $\quad 90.0 \%$

$$
>=80 \% \text { and }<90 \%
$$

Online access to view, plan, and maintain the annual $\mathrm{PhD}$ budget. $\quad 89.6 \%$

Online access to a description about the time plan as a PhD student. $\quad 89.5 \%$

Be able to plan and maintain a set of milestones: to see the current position in the entire PhD $\quad 86.2 \%$ process, the past and future tasks/steps.

Online access to a PhD forum for peer communications: discuss about questions, problems, $80.8 \%$ research ideas, etc.

$$
>=50 \% \text { and }<80 \%
$$

Access to an Idea Bank to find other researchers working on similar subjects/area. $\quad 75.5 \%$

Portfolio (or CV producing) function to make a list of your skills and expertise, and show a list $74.4 \%$ of your publications. This is aimed to facilitate $\mathrm{PhD}$ students to convert the information into a PDF file and use it as their latest CVs.

Online access to software tutorial videos, regarding specific data analysis/reference/language $\quad 72.9 \%$ development tools.

Access to video tutorials regarding how to access scientific databases (access to the library $\quad 72.4 \%$ databases and how to search for a scientific article).

Access to videos with previous $\mathrm{PhD}$ students' presentations of personal experiences and $50.0 \%$ advice regarding their $\mathrm{PhD}$ studies.

The results from statistical text mining on open questions showed that there were several words the respondents used in describing the problems they had and the solutions they proposed in order to enhance an ICT-based support system. As shown in Figure 2, the measures of term frequency on the open-ended responses of the questionnaire are used to visualize the most frequently used words in responding to the open-ended questions. The more frequent the term is used, the bigger the term is shown in the figure. 


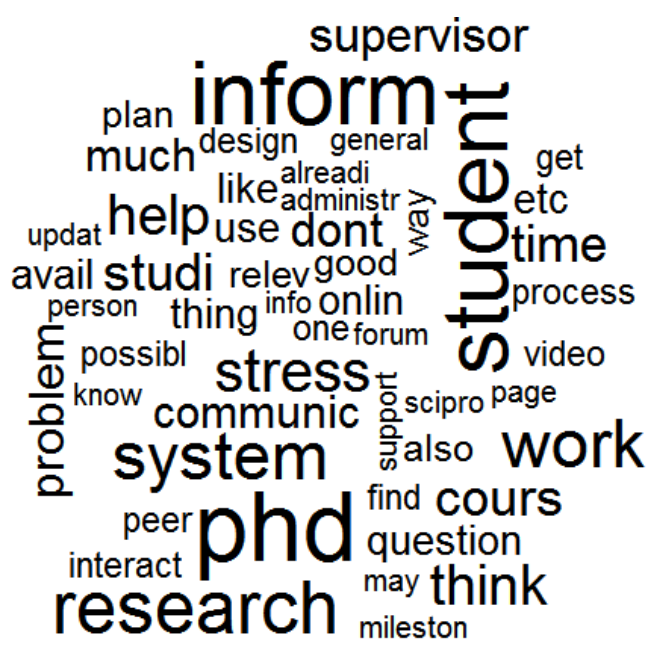

Figure 2. Word cloud of the most frequently used words in the responses and reflections to the open questions.

The word cloud in Figure 2 shows the most frequent terms the respondents used when discussing the problems and the solutions. Despite that the highlighted words in the word cloud may not strongly backup for concrete arguments about the problems and needs, such summarization would lead to identify focusses of the responses, which may be useful in design and development of an ICT support system (e.g., inform equals information which is connected to the information requirements; communication which is connected to the need for better communication channels; research which is connected to the importance of doing research and the focus on the requirements to facilitate research and the research process; stress which is an important issue in the process and supporting the PhD education through the use of ICTSS may positively affect reducing stress; and time as a factor to successfully manage the PhD education and the PhD students' stress levels). In addition to Figure 2, Table 3 also shows some of the responses to the open-ended questions regarding the positive and negative reflections regarding the usefulness of video resources in $\mathrm{PhD}$ education.

Table 3

PhD Students' Perception about the Usefulness of Video Resources in PhD Education

\begin{tabular}{|c|c|}
\hline $\begin{array}{l}\text { Positive responses about the use of video } \\
\text { resources }\end{array}$ & $\begin{array}{l}\text { Negative responses about the use of video } \\
\text { resources }\end{array}$ \\
\hline $\begin{array}{l}\text { "Sounds like a good idea I strongly prefer textual } \\
\text { descriptions to videos." }\end{array}$ & $\begin{array}{l}\text { "... it is difficult to acquire information from } \\
\text { video tutorials (I'm perhaps too old)." }\end{array}$ \\
\hline "Videos could be supplementary for the text." & "Is not of interest." \\
\hline "In each 3 minutes of video about $500-600$ & "Waste of resources and time to develop this." \\
\hline words are covered." & ng classes is a key \\
\hline "May & valu \\
\hline $\begin{array}{l}\text { The video has to be relevant and concise, and be } \\
\text { interesting to watch." }\end{array}$ & "Why would I want to spend that little time I \\
\hline "Vid & in 5 \\
\hline & $\begin{array}{l}\text { minutes and then easily refer back to it later." } \\
\text { "Video learning is for lazy students who don't }\end{array}$ \\
\hline
\end{tabular}


In addition to the discussion above, regarding the use of video resources, there was an interesting contrast between the two groups of respondents, as shown in Table 3. Some respondents had positive reflections about the use of relevant and concise videos. They believed that the use of video in their PhD studies would be a helpful tool to save time and gain information more quickly and easily. Meanwhile, there was another group of respondents with negative reflections, who believed that using the video resources would not add any value to the system and might do the opposite. Acquiring the relevant information and referring to it later would be easier and more efficient by reading rather than watching videos. The respondents' views regarding the use of the videos in $\mathrm{PhD}$ education were very different and a group of the respondents believed that video resources could be very useful, while others did not share this opinion and were not very positive toward them. However, as shown in Table 2, this variation of opinions may be due to the different types of video resources: software tutorial videos, video tutorials regarding how to access scientific databases, and videos with previous $\mathrm{PhD}$ students' presentations. It is also a personal matter which learning methods (video- or text-based resources) learners would prefer to use as learning materials. Even though, these video-based items may not be as high priority as some other issues that were required by above 80 or $90 \%$ of the $\mathrm{PhD}$ students (shown in Table 2), these type of recourses are still important since at least half of the respondents believed in the usefulness of this type of resource.

Based on the description above and the closed questions of the study about stress, $76 \%$ of the respondents felt extra stress from their PhD studies. The results showed that $50 \%$ of the respondents indicated that the use of ICTSS would be useful to reduce their stress (by having better control of the situation, keeping track of the study process, and getting information when needed), 30\% were neutral, and around 20\% did not find the system useful to reduce their stress. Table 4 shows both positive and negative responses to the open-ended questions regarding the usefulness of the ICTSS for reducing the stress in their PhD education.

Table 4

PhD Students' Perceptions about the Usefulness of the ICTSS for Reducing the Stress in their PhD Education 


\begin{tabular}{|l|l|}
\hline & $\begin{array}{l}\text { "Knowing where I am in my process, done courses, finished thesis credits, how my PhD annual budget is, } \\
\text { etc., would ease my stress quite a lot". } \\
\text { "That would help me see during what periods I might be overbooked and to prevent stress. But it needs to } \\
\text { be easily manageable". } \\
\text { "Having a planned set of milestones, open forum for peer communications, the ability to update the PhD } \\
\text { study plan online will reduce the stress". } \\
\text { "Transparency in all the parts of PhD work in online is very helpful for both the student as well as the } \\
\text { supervisors for managing the work. I believe all those proposed activities serve this purpose". } \\
\text { "Tracking progress of courses/credits and time spent on different activities study \& research planning and } \\
\text { following up planning and tracking percentages of work for different types of activities will help reducing } \\
\text { the stress". } \\
\text { "useful monitoring the study plan" } \\
\text { "Access to information would reduce stress for me, since the things I fret about are often related to things } \\
\text { I simply don't know - which means that I can't properly assess how much work will be required". } \\
\text { "List of relevant journals and conferences in my field will be useful". } \\
\text { "Transparency in all the parts of the PhD work (in online form) will be very helpful for managing the } \\
\text { work. I believe all those proposed activities serve this purpose to reduce the stress". }\end{array}$ \\
\hline \multirow{2}{*}{ "I don't think a new system reduces stress very much; it may also add stress to have yet another thing to } \\
handle. But, if it is well done it may help to provide better overview, which in turn may create a \\
deterministic situation". \\
"An ICT system does not reduce stress in itself, only people, processes, and organizational culture can do \\
that. Don't be technological determinist".
\end{tabular}

\section{Discussion}

As the results of this study show, most of the respondents believed that designing an ICTSS for PhD education could facilitate easier and more convenient interactions for all three types of interactions (as discussed by Moore, 1989). This means that the use of ICTSS in the PhD education may facilitate flexible and open learning and communication, which learners believe would be useful both on- and off-campus. The ICTSS may even be used to arrange face-to-face meetings and plan for physical interaction. However, designing and developing an ICTSS and providing online information resources and communication channels is not a replacement for individual supervision meetings or interpersonal communications. It is in order to facilitate the interaction on distance and give the PhD students the possibility of having access to the information and online communication channels off-campus or from a distance.

As discussed by Christie and Jurado (2013), the result of this study also showed that insufficient supervision and lack of communication with supervisors was an important issue, and $\mathrm{PhD}$ students expected better interaction and more support from supervisors. However, for the respondent group in this study, this might not be the biggest concern, when designing an ICTSS. As shown by Table 1, higher priority interaction issues were the following: access to the structured online e-resources and information (also discussed by Jones, 2013; Aghaee et al., 2014), better online peer communication (also discussed by Christie \& Jurado, 2013; Guilford, 2001; Aghaee \& Hansson, 2013), and more appropriate timelines.

Based on the responses to the close-ended and open-ended questions, more than $70 \%$ of the respondents requested availability of structured information resources, guidelines for essential steps, and better support for peer communications. As mentioned by the respondents, information acquisition by accessing structured e-resources, online planning and updating the PhD study plan, and communicating with peers through specifically designed interaction channels could be useful for the $\mathrm{PhD}$ students and have the potential of reducing the stress of the $\mathrm{PhD}$ students. Based on the results of the study, Figure 3 reflects the 
PhD students' perspectives on the problems and the requirements of an ICTSS as a solution to part of the problems. In Figure 3, the three categories of resources (useful resources for almost all PhD students, useful resources for most of the PhD students, and additional resources) were developed based on the agreement percentages of the respondents with the usefulness of each resource and function (as shown in Tables 1 and 2).

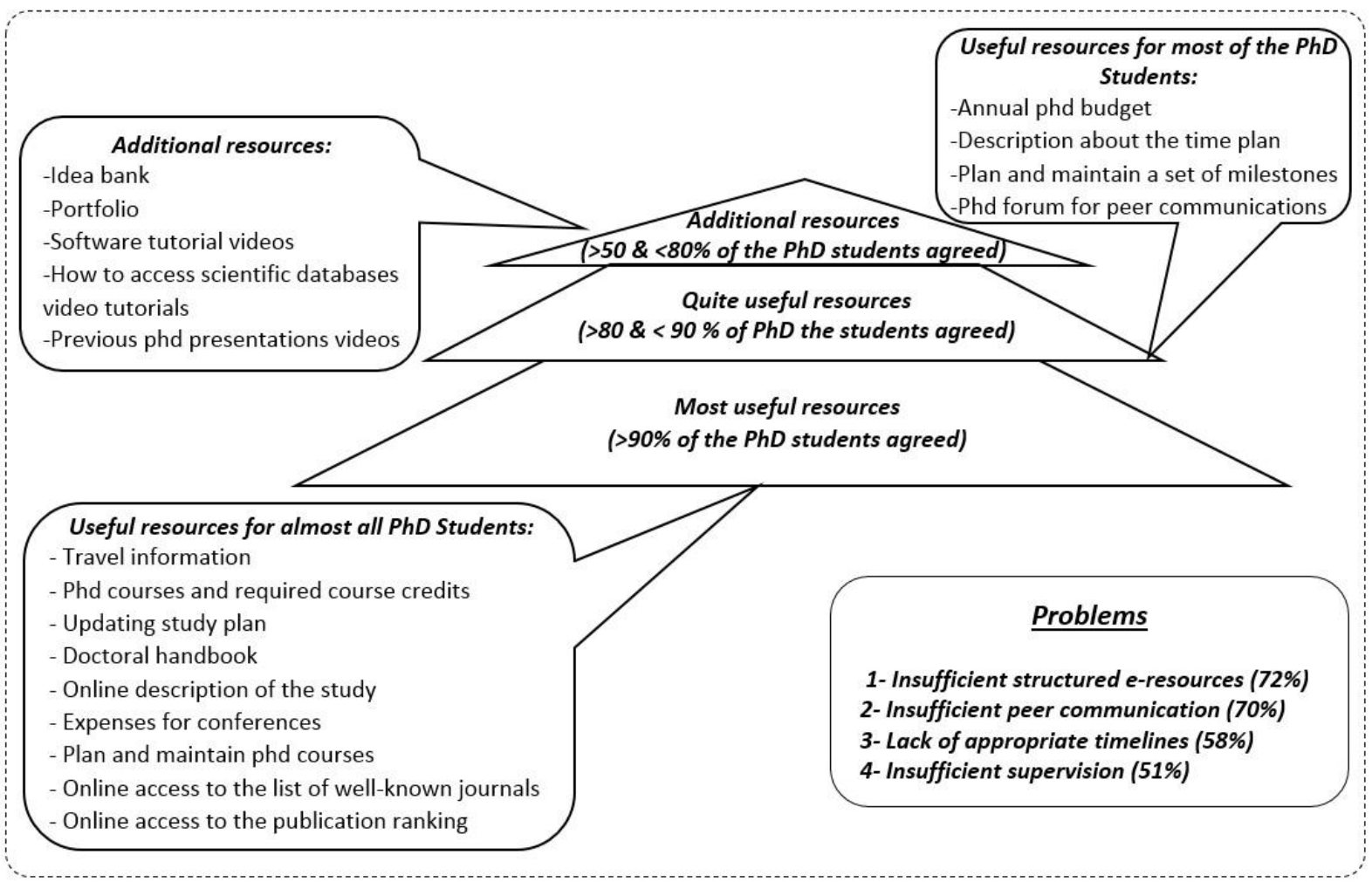

Figure 3. The categorized resources into three different levels based on the respondents' perspectives (discussed in Tables 1 and 2).

Based on Table 2 and Figure 3, the following issues have been developed to illustrate how each functionality or recourse discussed above can be useful to reduce the four categories of the problems in the PhD education. As mentioned below, most of these functionalities indirectly support learners by providing access to the information through resources and communication channels, which also saves learners time and reduces their stress. It also enables learners to use their supervision time to develop their research rather than focusing on getting general information from their supervisors. The following list shows how the functionalities or recourses can be useful to reduce the interaction problems in $\mathrm{PhD}$ education.

1. Insufficient online information: PhD requirements, the study process, goals, etc

- By accessing clear online information regarding the travel information and how to book travel, learners will be more independent from their supervisors or administrative staff to be able to book travels through the ICTSS.

- By availability and online access to the information about the available $\mathrm{PhD}$ courses, obligatory courses, recommended courses, and required course credits in each phase of the $\mathrm{PhD}$ education, the $\mathrm{PhD}$ students will not need to ask for information from their supervisors or the director of postgraduate 
studies.

- By accessing the online categorized information from the doctoral handbook, the PhD students know where to refer, when they would like to know about the rights and regulations, or other important information, which are normally scattered around on different university webpages.

- Electronic version of the approval (e-signature) for applying to a conference and obtaining the confirmation of the expenses paid by the institution will make the process simpler and even possible to be done remotely when the $\mathrm{PhD}$ students cannot physically be at the institution (facilitates flexible and distance access).

- Availability of information regarding the list of the well-known journals and conferences in different research areas will support learners to learn about them and be able to choose from the list instead of either spending much more time to find them independently or get the information from their supervisors.

- Access to the online information regarding the publication ranking (such as Norwegian ranking, Finnish ranking, or any other international ranking systems) and information about the impact factor of each publication makes the $\mathrm{PhD}$ students learn more about quality publishers and proceedings (journals and conferences) and what are not accredited by the institution. It is also important for the PhD students to see the rank of their own publications.

- By having a system to enable PhD students to control and check their annual PhD budget through an online system, they would not need to ask administrative staff about how much of their annual budget is remaining at different points per year and it will make planning easier for the learners and the supervisors.

- Possibility of providing portfolio function to make a list of learners' skills, expertise, and publications will make the process easier to apply for scholarships, grants, summer courses, and join different projects. This facilitates PhD students to convert the information into a PDF file and use it as their latest portfolio (CV) connected to their recent competencies and publications.

- Accessing video tutorials regarding specific data analysis, references, and language development tools and other useful software will support and motivate learners to use appropriate tools in their research by learning about the existing systems and get information about how and in which context they can use the tools. This can also be accomplished with mobile applications, which enhances the online and distance educational communication.

- Video tutorials regarding how to access scientific databases, such as online libraries or searching on Google Scholar. Accessing other researchers' publications in similar research areas or at the same department will support learning about accessing the scientific references and resources.

2. Insufficient online peer communication: synchronous and asynchronous interactions

- An online PhD forum through the ICTSS for peer communications will facilitate PhD students to communicate easier and faster, even when they are not on campus to discuss about questions, problems, research ideas, and so on. This forum can also include a section, in which the willing supervisors can also join the discussions and answer the questions. However, the PhD students should be able to choose to write on the PhD peer forum or the public forum with the supervisors.

- An online Idea Bank to find other researchers' ideas, publications, projects, or even research topics to provide possibilities of communications and collaboration among researchers and $\mathrm{PhD}$ students. This 
can also be useful to know who at the same department is working with what subjects and be able to contact the person in case of ideas for collaboration.

- Videos with previous PhD students' presentations of their personal experiences and advice regarding their PhD studies would be useful for some PhD students to learn from the senior PhD students and be able to know them while they are studying at the same department. This would help PhD students' peer communication and networking, while knowing about the subject area with which the others work. The presentations could be very short and just give a simple message to share the opinions with their fellows.

3. Lack of appropriate timelines: milestones or internal deadlines

- Online planning and possibility of updating the individual study plan online will facilitate mobility of access to plans from previous years and have a structured archive of the study plans from the beginning of the PhD education to the end. This may be useful since the PhD students and supervisors get the opportunity of comparing the study plans from different years to monitor the educational progress, achievements, publications, and fulfillment of the different stages of the PhD education.

- By having the possibility of planning and maintaining PhD courses online, the PhD students can get a list of the finished courses, obligatory courses, reading courses, international courses, and the courses that they plan to take. This also gives supervisors the opportunity to keep track of which courses the PhD students have taken or plan to take and hence can provide guidelines and suggestions in line with the plans.

- Online access to a description about the time plan as a PhD student will reduce confusion, especially at the beginning of the PhD education and support PhD students to get a better vision of the entire $\mathrm{PhD}$ education process. This could have been provided by the supervisors to help the PhD students to get into the $\mathrm{PhD}$ education more quickly instead of getting too confused or lost from the beginning.

- Be able to plan and maintain a set of milestones will support the PhD students to see the current position in the entire $\mathrm{PhD}$ process, the past phases and achievements, and the future tasks and steps. The milestones could be defined by the PhD students together or with the guidelines of their supervisors. Having a PhD education that is too flexible and without milestones may reduce the achievement of the learners. Hence, milestones will guide learners how to plan, how to fulfill the plans, and how to achieve smaller outcomes in order to get a vision of the $\mathrm{PhD}$ education process and reach the ultimate goal, which is finishing their PhD education and getting their PhD degrees.

4. Insufficient supervision and lack of communication with supervisor(s)

- Online planning and the possibility of updating the individual study plan by the use of the ICTSS will facilitate communication between the supervisors and $\mathrm{PhD}$ students. It is important to keep the records of the supervisors' advice and provide information for the $\mathrm{PhD}$ students, especially in the beginning of the $\mathrm{PhD}$ education. This function will help archive all the information, guidelines, and even the final copy of the study plan for each year in order to refer back to it in the future. The system will hence reflect whether the PhD students get adequate guidelines from their supervisors to plan and update the study plan, especially in the beginning. The system may help motivate supervisors to be more active and pay more attention to PhD students' study plan. In addition, supervisors can also access the study plan and keep better track of the $\mathrm{PhD}$ student's achievements, conference attendances, course planning, and so on.

- Supervisors can communicate with the PhD students by providing and updating an online list of well- 
known journals and conferences in their research areas to support learners to obtain information about them and be able to plan for submitting scientific papers. This also enables learners to learn about their supervisors' suggestions and guidelines about the publications, while having the possibility of deciding which journal or conference would suit their own research papers.

- By deciding on a set of milestones, supervisors will know more about PhD students' sub-tasks for achievements and may have better control of keeping track when the PhD students need help or get stuck to help them and provide them with the required guidelines. Independence in a $\mathrm{PhD}$ education is part of the process; however, providing appropriate guidelines and required information and having smaller deadlines to monitor the achieved results is another important part of the PhD education.

- By accessing the online, categorized information from the doctoral handbook, the PhD students as well as supervisors, can have access to the important and sorted information in order to learn about their rights, responsibilities, and tasks, as well as the university's rules and regulations.

The contrast of the $\mathrm{PhD}$ students' reflections regarding the video resources was an interesting issue (discussed by Schmeck, 1988; Liu \& Reed, 1995; Silberman, 1996) to investigate why this contrast existed and to find out more details about what the motivations were and the thoughts behind these reflections.

Silberman (1996) discusses different strategies, when learning matters. Moreover, Kettanurak, Ramamurthy and Haseman (2001) discussed that positive interactions may influence users' attitudes and hence it consequently leads to enhance users' achievements and learning. However, as discussed above, this variation of opinions may be connected to the learners' research areas, the different types of video resources, how the learners use the video resources, and what types of video resources they mainly use in their education. Even though the video-based items may not be as high priority as most useful or quite useful information resources (required by above 80 or $90 \%$ of the $\mathrm{PhD}$ students), they are still important since more than half of the respondents believed in the usefulness of these three types of video resources and the respondents reflected positively on the use of video resources. Moreover, many respondents added comments (shown in Table 3) to the open-ended questions regarding the use of the video resources.

Some prefer to learn through text, while others learn more easily through pictures and visualization, communication, videos, or combinations. The idea here is to reflect on the diversity of people in a group, such as PhD students. It may also depend on other factors, such as the quality of the produced videos, $\mathrm{PhD}$ students' study discipline, and learning and teaching methods. Moreover, as discussed by Durette et al. (2014), although PhD students' training and learning experiences may be different from one to another depending on different factors, a substantial part of its outcomes is constant. This means that there is not a uniform way of learning, but video based, text-based and, graph-based resources may be useful in different circumstances and for different purposes.

A similar case concerns the use of ICT for PhD studies to reduce the stress level of the students. Based on the discussion above, stress is defined as a lack of control of a situation or tension resulting from adverse or very demanding circumstances. The result of this study showed that $76 \%$ of the respondents felt extra stress from their PhD studies, while the rest did not share this feeling. There was no general rule to show whether a support system would help reduce stress or not. "People react differently to the same stimuli" as mentioned by one of the respondents. There were different perspectives, both positive and negative reflections on the effect of using ICTSS for PhD education. More than half of the respondents indicated that an ICTSS would help them to manage tasks more efficiently, and it might hence reduce their stress. 
Based on the respondents' reflections shown in Table 4, there were many resources and functions that might enhance the control of the situation and facilitate better study management. Acquiring information might also positively affect the management and reduction of stress. However, a small group of respondents did not find the direct connection of using a support system to reduce stress.

\section{Limitation and Reflection}

A multi-disciplinary study with the similar research question would increase the generalizability of the study result and conclusion. Access to the PhD students (the institution's name has been removed during the double-blind review) was only possible through the university email. In some cases, the PhD students might have stopped their $\mathrm{PhD}$ education or the emails might have become obsolete. To assess the real reflections about the support system, a test group of the first pilot of ICTSS for PhD education would add value to the development process. Supervisors' perspectives, to examine the problems and solutions from another point of view, would also add value to the study.

\section{Conclusion}

The low completion rate and slow progress in $\mathrm{PhD}$ education have been highlighted by different studies. Universities strive to improve throughput and quality in their $\mathrm{PhD}$ education. However, different problems and influential factors besides increasing number of $\mathrm{PhD}$ students make these efforts extra challenging. This study investigated the most important interaction problems in $\mathrm{PhD}$ education from $\mathrm{PhD}$ students' point of view and how PhD students think that an ICTSS will facilitate reducing interaction problems and stress in a PhD degree. Most previous studies focused on problems related to supervision, however this study found that there were other important issues besides supervision problems. The results revealed a number of problems in $\mathrm{PhD}$ education, the most prevalent being insufficient online information (72\% of respondents), insufficient online peer communication ( $70 \%$ of respondents), lack of appropriate timelines ( $58 \%$ of respondents), and insufficient supervision ( $51 \%$ of respondents).

From the results, one main concern of the $\mathrm{PhD}$ students was to get online access to the critical information, such as information about educational requirements and goals, tasks and responsibilities, the study process and the courses, the administrative information, traveling, and budgeting. Communication online was also shown to be important, especially for enhancing peer interaction but also for communicating with the supervisors. Most of the respondents rated the usefulness of many online information resources and functionalities of the ICTSS as very or rather high. More than 90\% of the respondents indicated the usefulness of the following: travel information, plan and maintain $\mathrm{PhD}$ courses and required course credits, updating and accessing the individual study plan online, structured and online information from the doctoral handbook, managing the conference expenses, and access to the list of the well-known journals and the publication ranking. More than $80 \%$ of the respondents indicated the usefulness of online access to the following: the annual $\mathrm{PhD}$ budget, description about the time plan, plan and maintain a set of milestones, a PhD forum for peer communications, and even supporting the learnersupervisor communication and conversation. The rest of the functionalities were indicated as useful by more than $50 \%$ but by less than $80 \%$ of the respondents. 
The contribution of this study is a complement to the previous studies and reflects the importance of including PhD students in different study situations and learning styles in the design of an ICTSS. It also raises the question of how an ICTSS can be useful to reduce interaction problems. A holistic view of what the main problems were and details about what resources would be useful for PhD students to reduce these interaction problems were listed above. The text responses provided by the respondents were analyzed using text-mining techniques and showed that the students mostly discussed courses, communication, information, stress, and so on. These issues were covered by the resources and functionalities of the ICTSS to provide support, reduce the interaction problems, and facilitate $\mathrm{PhD}$ students to achieve better educational outcomes with more control of their educational processes with less stress. The results of this study provided some rudimentary ideas that developing an ICTSS can facilitate better information access and communication in $\mathrm{PhD}$ education to reduce the interaction problems. This would strengthen the ICTSS development process to more likely be able to offer open and flexible support and contribute to $\mathrm{PhD}$ education with more effective study situations both on campus and off campus.

As mentioned above, stress was a concern for a large group of $\mathrm{PhD}$ students at the institution. Approximately three out of four of the responding $\mathrm{PhD}$ students experienced increased stress due to their 
study situation. Concerning the usefulness of ICTSS, the results turned our attention in a certain direction: towards a greater transparency in $\mathrm{PhD}$ education, including a better overview of relevant information, a tool for planning and reviewing, and in general, easier access to information and interaction. This result indicates that a certain specific information and guidance support is required to reduce the stress of $\mathrm{PhD}$ students. Based on the findings, an ICTSS will support PhD students to have better control of the situation by finding the information through online structured resources and having better communication channels. The ICTSS may support interaction with peers and supervisors or arrange face-to-face communication. However, as mentioned above, an ICTSS is only considered as an online complementary support to the face-to-face interactions and information resources and will provide support for the $\mathrm{PhD}$ students and cannot function as a supervision system without supervisors. Hence, designing and developing an ICTSS is not a replacement for individual supervision meetings or face-to-face peer communications, but facilitates better control and arrangement of the different types of interaction.

\section{References}

Abbott, C. (2003). ICT: Changing education. New York, NY: Routledge.

Aghaee, N. (2013) Finding potential problems in the thesis process in higher education: Analysis of emails to develop a support system. Education and Information Technologies, 2O(1), 1-16. doi:10.1007/s10639-013-9262-z

Aghaee, N., \& Hansson, H. (2013). Peer Portal: Quality enhancement in thesis writing using self-managed peer review on a mass scale. The International Review of Research in Open and Distributed Learning, 14(1), 186-203.

Aghaee, N., Hansson, H., Tedre, M., \& Drougge, U. (2014). Learners' Perceptions on the Structure and Usefulness of e-Resources for the Thesis Courses. European Journal of Open, Distance and Elearning, 17(1), 154-171. DOI: 10.2478/eurodl-2014-0011.

Aghaee, N., Karunaratne, T., Smedberg, Å., \& Jobe, W. (2015). Communication and Collaboration Gaps among PhD Students and ICT as a Way Forward: Results from a Study in Sweden. In Proceedings of E-Learn: World Conference on E-Learning in Corporate, Government, Healthcare, and Higher Education 2015 (pp. 237-244). Association for the Advancement of Computing in Education.

Ali, A., \& Kohun, F. (2007). Dealing with social isolation to minimize doctoral attrition: A four stage framework. International Journal of Doctoral Studies, 2(1), 33-49.

Christie, M., \& Jurado, R. G. (2013). Using communicative action theory to analyse relationships between supervisors and PhD students in a technical university in Sweden. Högre Utbildning, 3(3), 187197.

Cohen, L.; Manion, L. and Morrison, K. (2007). Research Methods in Education. (6th ed). New York: Routledge. 
Cook, C., Heath, F., \& Thompson, R. L. (2000). A meta-analysis of response rates in web- or internetbased surveys. Educational and Psychological Measurement, 6o(6), 821-836.

Creswell, J. W. (2012). Qualitative inquiry \& research design: Choosing among five approaches (3rd ed.). Thousand Oaks, CA: Sage.

Delamont, S., Atkinison, P., \& Parry, P. (2004). Supervising the doctorate: A guide to success. Milton Keynes: Open University Press.

Denscombe, M. (2010). The good research guide: For small-scale social research projects. Location: McGraw-Hill International.

Dillman, D. A. (1978). Mail and telephone surveys (Vol. 3). New York, NY: Wiley.

Durette, B., Fournier, M., \& Lafon, M. (2014). The core competencies of PhDs. Studies in Higher Education, (ahead-of-print), 1-16. doi: 10.1080/03075079.2014.968540

Fiske, P. (2011). What is a PhD really worth? Nature, 472(7343), 381-381.

Gannon, F. (2006). What is a PhD? EMBO Reports, 7(11), 1061-1061.

Guilford, W. (2001). Teaching peer review and the process of scientific writing. Advances in Physiology Education, 25(3), 167-175.

Haksever, A. M., \& Manisali, E. (2000). Assessing supervision requirements of PhD students: The case of construction management and engineering in the UK. European Journal of Engineering Education, 25(1), 19-32.

Handal, G., \& Lauvås, P. (2008). Forskarhandledaren. Stockholm, Sweden: Studentlitteratur.

Hockey, J. (1991). The social science PhD: A literature review. Studies in Higher Education, 16(3), 319332.

Hockey, J. (1994). New territory: Problems of adjusting to the first year of a social science PhD. Studies in Higher Education, 19(2), 177-190.

Högskoleverket, National Agency for Higher Education (2012). The Swedish Higher Education System. Retrieved from https://www.uhr.se/globalassets/_uhr.se/bedomning/utlansk-akademiskutbildning/the_swed_high_system.pdf Jones, M. (2013). Issues in doctoral studies - Forty years of journal discussion: Where have we been and where are we going? International Journal of Doctoral Studies, 8. Retrieved from http://ro.uow.edu.au/cgi/viewcontent.cgi?article=1177\&amp;context=buspapers

Kandiko, C. B., \& Kinchin, I. M. (2012). What is a doctorate? A concept-mapped analysis of process versus product in the supervision of lab-based PhDs. Educational Research, 54(1), 3-16. 
Karasek, R., \& Theorell, T. (1990). Healthy work: Stress, productivity, and the reconstruction of working life. New York, NY: Basic Books.

Kettanurak, V. N., Ramamurthy, K., \& Haseman, W. D. (2001). User attitude as a mediator of learning performance improvement in an interactive multimedia environment: An empirical investigation of the degree of interactivity and learning styles. International Journal of Human-Computer Studies, 54(4), 541-583.

Kyvik, S., \& Olsen, T. B. (2013). Increasing completion rates in Norwegian doctoral training: Multiple causes for efficiency improvements. Studies in Higher Education, 39 (9), 1668-1682 .

Lazarus, R. S., \& Folkman, S. (1984). Stress, appraisal and coping. New York, NY: Springer.

Langrish, J. (2000). Not everything made of steel is a battleship. In A. A Editor, Doctoral education in design: Foundations for the future. Conference Doctoral Education for Design: Foundation for the Future. La Clusaz 8 - 14 July 2000. Conference Proceedings pp . 297 - 305. Staffordshire University Press.

Lemon, J. S. (2007). The effect of reminder intervals on response rates for web surveys. In A. A. Editor, Survey and statistical computing IV: The impact of technology on the survey process (pp. 1-10). Location: Association for Survey Computing.

Lindén, J. (1998). Handledning av doktorander. Stockholm, Sweden: Nya Doxa.

Lindén, J., Ohlin, M., \& Brodin, E. M. (2013). Mentorship, supervision and learning experience in PhD education. Studies in Higher Education, 38(5), 639-662.

Liu, M., \& Reed, W. M. (1995). The relationship between the learning strategies and learning styles in a hypermedia environment. Computers in Human Behavior, 10(4), 419-434.

Lönn Svensson, A. (2007). Det beror på, Erfarna forskarhandledares syn på god handledning (Doctoral dissertation, University College of Borås). Retrieved from http://bada.hb.se/handle/2320/1802

McCormick, R. (2004). Collaboration: The challenge of ICT. International Journal of Technology and Design Education, 14(2), 159-176.

McCormack, C. (2005). Is non-completion a failure or a new beginning? Research non-completion from a student's perspective. Higher Education Research \& Development, 24(3), 233-247.

Moore, M. (1989). Three types of interactions. The American Journal of Distance Education, 3(2), 1-6.

Moore, M. G., \& Kearsley, G. (1996). Distance education: A systems view. Boston, MA: Wadsworth.

Park, C. (2005). New variant PhD: The changing nature of the doctorate in the UK. Journal of Higher Education Policy and Management, 27(2), 189-207. 
Randolph, J. J. (2007). Multidisciplinary methods in educational technology research and development. Location: HAMK Press/Justus Randolph.

Richards, C. (2005). The design of effective ICT-supported learning activities: Exemplary models, changing requirements, and new possibilities. Language Learning \& Technology, 9(1), 60-79.

Richards, C. (2006). Towards an integrated framework for designing effective ICT-supported learning environments: The challenge to better link technology and pedagogy. Technology, Pedagogy and Education, 15 (2), 239-255.

Rudd, E., \& Hatch, S. R. (1968). Graduate study and after. London, UK, Weidenfeld \& Nicholson.

Schmeck, R. R. E. (1988). Learning strategies and learning styles. Illinois: Plenum Press.

Shannon, A. G. (1995). Research degree supervision: More mentor than master. Australian Universities' Review, 38(2), 12-15.

Silberman, M. (1996). Active learning: 101 strategies to teach any subject. Des Moines, IA: Prentice-Hall.

Sinclair, M. (2004). The pedagogy of 'good' PhD supervision: A national cross-disciplinary investigation of PhD supervision. Canberra, Australia: Australian Government, Department of Education, Science and Training.

Tinio, V. L. (2003). ICT in education. New York, NY: United Nations Development Programme-Asia Pacific Development Information Programme.

Welsh, J. M. (1980). The postgraduate student: Progress and problems (Doctoral dissertation). Available from EThOS e-theses online service. (EThOS ID uk.bl.ethos.291474).

Wisker, G. (2012). The good supervisor. London, UK: Palgrave Macmillan.

Wright, T., \& Cochrane, R. (2000). Factors influencing successful submission of PhD theses. Studies in Higher Education, 25(2), 181-195.

Wright, J., \& Lodwick, R. (1989). The process of the PhD: A study of the first year of doctoral study. Research Papers in Education, 4(1), 22-56. 


\section{Appendix}

\section{Table A1}

Result of the Open-Ended Questions Regarding the PhD Students' Perspectives on the Additional Problems

\section{Additional problems mentioned by the PhD students}

Relevant information required; "... the main problem isn't communication ..., but rather the availability of information". "Furthermore, finding relevant information often becomes an exercise in frustration since the relevant information is spread across a number of different documents".

Information about using the system; Poor communication with ICT and lack of knowledge of using the systems.

Information requires about courses; when courses are given, when they start, and how to apply for them, etc.

More information and training about the ethical issues is required; The ethical training for PhD students in Sweden is quite insufficient. Improvement of the ethical skills is very slight or even deteriorated in course of their education.

Both online and face to face peer interaction requirement; "peer communication online (asked above) is only one type, $\mathrm{f} 2 \mathrm{f}$ and real-world group and peer to peer communication is more substantial and heavily lacking."

Knowledgeable supervision in specific area of knowledge is required; There is a need for a supervisor that is an expert or at least interested in the area of work of the PhD student(s).

Supervisor support is required; Supervisors have to think more about the PhD students, rather than of what they can gain of the study that is done by the PhD students. They need to cover what is relevant to supervision not their own benefit of the research.

\section{Table A2}

Result of the Open-Ended Questions Regarding the PhD Students' Suggestions About How to Reduce the Problems. 
Specific information acquisition; "I would like inform ation that is not just information, but information RELEVANT FOR ME."

Updated information acquisition; PhD students require new information: "... it would be easier to see new info and to navigate in what is important to me". The respondent also mentions that "...some information are either cu rrently not available or we are not aware a bout, but would disti nctly be important."

Information and guidance acquisition; wishing for a system to guide $\mathrm{PhD}$ students th rough the process of filling in the forms such as travel documents and expenses, and help to update the study plan, getting information about the status of the ann ual $\mathrm{PhD}$ budget, etc.

Information and guidance acquisition; Since one department cannot deliver all the relevant and req uired cou rses for the $\mathrm{PhD}$ st udents, information should be given about which other universities (which cou ntries) provide such cou rses and $\mathrm{PhD}$ students are allowed to ta ke them. Moreover, cla rify what a re the conditions and specifications.

Information and guidance acquisition; According to a respondent, based on a regular survey, the ethical training for $\mathrm{PhD}$ students in Sweden is quite insufficient and the $\mathrm{PhD}$ students need more information and resou rces in this regard, besides other relevant issues. "Ethical cond uct would probably have a strong influence on how resea rch is conducted, and thereby its outcome, if it wou ld be given the space to do so."

Online information acquisition; On line informati on about the on-going projects at DSV with open research problems that suits a PhD research level would be of interest and useful. "Online information of the ongoing projects under DSV Professors with open resea rch problems that suits a PhD resea rch level."

Information acquisition; Publication for ums and their rankings a re already available online; but making the relevant infor mation to the $\mathrm{PhD}$ studies explicit and publicly available and accessibl e for the PhD students is useful.

Information acquisition about the existing information; Some useful infor mation is alrea dy available at the library specific presentations for research in each of the research areas, their specific practices, common methodologies, thesis structuring (including monograph or collection of papers, and why) etc. However, there is a need of refer ring to them and inform $\mathrm{PhD}$ students about the availability of such resou rce.

Information acquisition about the rights and entitlements; Providing information resources th at clearly outline $\mathrm{PhD}$ rights, responsibilities, entitlements, etc.

Planning: ICT enabled system can help to build a platform to provide a proper schedule, to be visible for all the releva nt parties, e.g. supervisors, peers, administration departments, etc.

Planning: A course guideline would be helpful in the way to design a check box for each course, possi ble to be checked by both PhD students and their supervisors: "I or my supervisor could check a box: "course A done" "obligatory course X lacking" "n individ ual credits passed " a nd we could press "print" and an u pdated version could be signed".

Planning: Possibility of updating the study plan on line and printing the updated version (i.e., in a PDF format) to be signed.

Peer interaction; "more peer comm unication would definitely add some values to the system and comm unication matter." "More peer commu nication wou ld be better". 
Athabasca

University

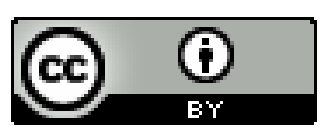

